\title{
Interval approach of time series forecasting by neural networks for the decision support system
}

\author{
Victor Dubolazov ${ }^{1 *}$, and Andrei Somov ${ }^{1}$ \\ ${ }^{1}$ Peter the Great St.Petersburg Polytechnic University, Polytechnicheskaya, 29, St. Petersburg, \\ 195251, Russia
}

\begin{abstract}
The article is devoted to the new method of preparation of time series data and its prediction made by neural networks. A detailed analysis of the methodology and comparison of the results with ARIMA method carried out. A full table of initial data and forecasting results for the export of goods and services for 2021 accompanies the article.
\end{abstract}

\section{Introduction}

Forecasting of time series of economic data is relevant and important for companies engaged in planning process in the various sectors of the economy. For example: logistics companies that planning optimal routes of cargo and seasonal loading of warehouse space, for industrial companies that are planning the production volume, for companies which entering to the new markets, international markets, that are planning the future sales growth and impact on competitors.

The availability of a fast and correct method of time series forecasting is usually the basis for building a modern, multi-parameter and proactive decision support system.

\section{Method}

The main algorithm of the method following:

- The data of time series of exports of goods and services from 1960 to 2016 are loaded into the table, for 180 countries (Table 1), source of the data [1];

- Data is prepared in a special way for a neural network: it organised in two columns, one input column and one output column. The data taken from the last ten years of the time series, and then it is coped the first five years into the input column, and the next five years into the output column. At the end, we have two columns of 895 rows each of 180 countries, like at the Table 2 [2].

\footnotetext{
* Corresponding author: somovspb@yandex.ru
} 
Table 1. A fragment of the initial data table, exports of goods and services for 180 countries, from 1960 to 2016, us dollar.

\begin{tabular}{|c|c|c|c|c|c|c|}
\hline Country Name & $\mathbf{2 0 1 1}$ & $\mathbf{2 0 1 2}$ & $\mathbf{2 0 1 3}$ & $\mathbf{2 0 1 4}$ & $\mathbf{2 0 1 5}$ & $\mathbf{2 0 1 6}$ \\
\hline Canada & $5,47 \mathrm{E}+11$ & $5,51 \mathrm{E}+11$ & $5,56 \mathrm{E}+11$ & $5,66 \mathrm{E}+11$ & $4,90 \mathrm{E}+11$ & $4,74 \mathrm{E}+11$ \\
\hline Belgium & $4,30 \mathrm{E}+11$ & $4,10 \mathrm{E}+11$ & $4,25 \mathrm{E}+11$ & $4,42 \mathrm{E}+11$ & $3,77 \mathrm{E}+11$ & $3,94 \mathrm{E}+11$ \\
\hline Brazil & $3,00 \mathrm{E}+11$ & $2,89 \mathrm{E}+11$ & $2,88 \mathrm{E}+11$ & $2,70 \mathrm{E}+11$ & $2,32 \mathrm{E}+11$ & $2,24 \mathrm{E}+11$ \\
\hline Central African Republic & $2,53 \mathrm{E}+08$ & $2,53 \mathrm{E}+08$ & $2,19 \mathrm{E}+08$ & $2,22 \mathrm{E}+08$ & $2,00 \mathrm{E}+08$ & $2,23 \mathrm{E}+08$ \\
\hline Gambia, The & $2,38 \mathrm{E}+08$ & $2,81 \mathrm{E}+08$ & $2,64 \mathrm{E}+08$ & $2,22 \mathrm{E}+08$ & $2,04 \mathrm{E}+08$ & $2,31 \mathrm{E}+08$ \\
\hline Grenada & $1,96 \mathrm{E}+08$ & $2,06 \mathrm{E}+08$ & $2,14 \mathrm{E}+08$ & $2,33 \mathrm{E}+08$ & $2,37 \mathrm{E}+08$ & $2,41 \mathrm{E}+08$ \\
\hline
\end{tabular}

The full table is available here [2].

Table 2. A fragment of a table with two columns for training the neural network, $X$ - input column and Y- output.

\begin{tabular}{|c|c|c|c|c|c|}
\hline & \multicolumn{5}{|c|}{ Canada } \\
\hline $\mathbf{X}$ & $5,00 \mathrm{E}+11$ & $5,32 \mathrm{E}+11$ & $3,90 \mathrm{E}+11$ & $4,69 \mathrm{E}+11$ & $5,47 \mathrm{E}+11$ \\
\hline $\mathbf{Y}$ & $5,51 \mathrm{E}+11$ & $5,56 \mathrm{E}+11$ & $5,66 \mathrm{E}+11$ & $4,90 \mathrm{E}+11$ & $4,74 \mathrm{E}+11$ \\
\hline
\end{tabular}

- Then the data segmented into two segments: countries with large exports (Fig 1) and countries with small exports (Fig 2). If this is not done, there will be large forecasting error for low-exporting countries (see Fig. 9);

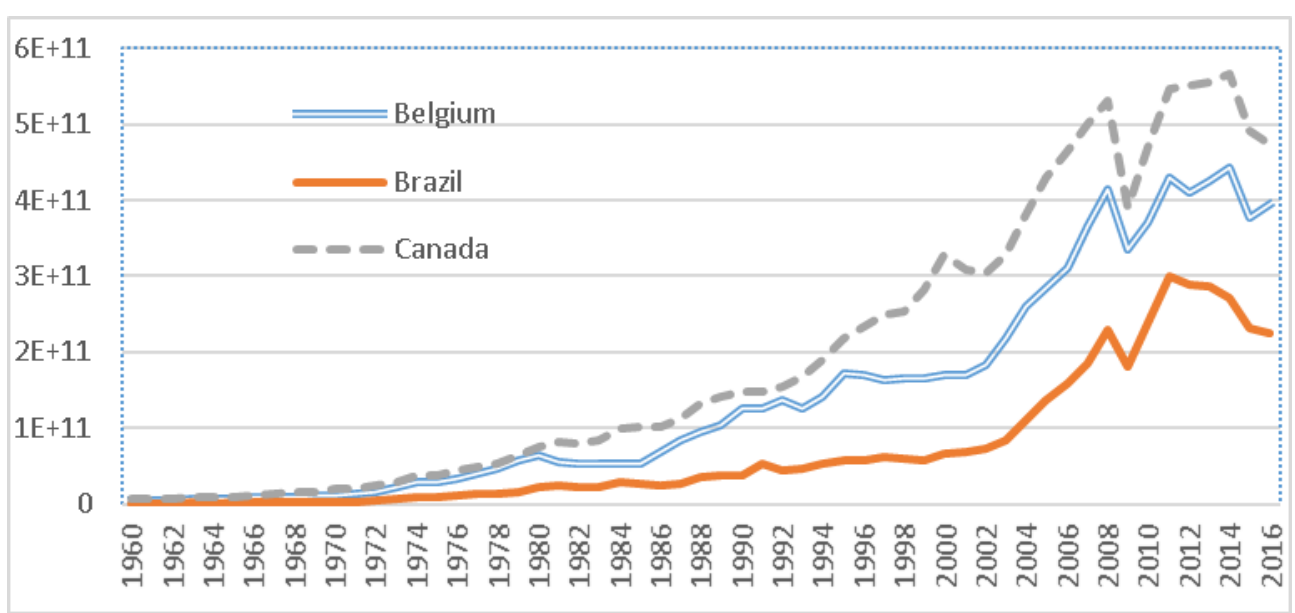

Fig. 1. Data on exports of goods and services for high-exporting countries, us dollar. 


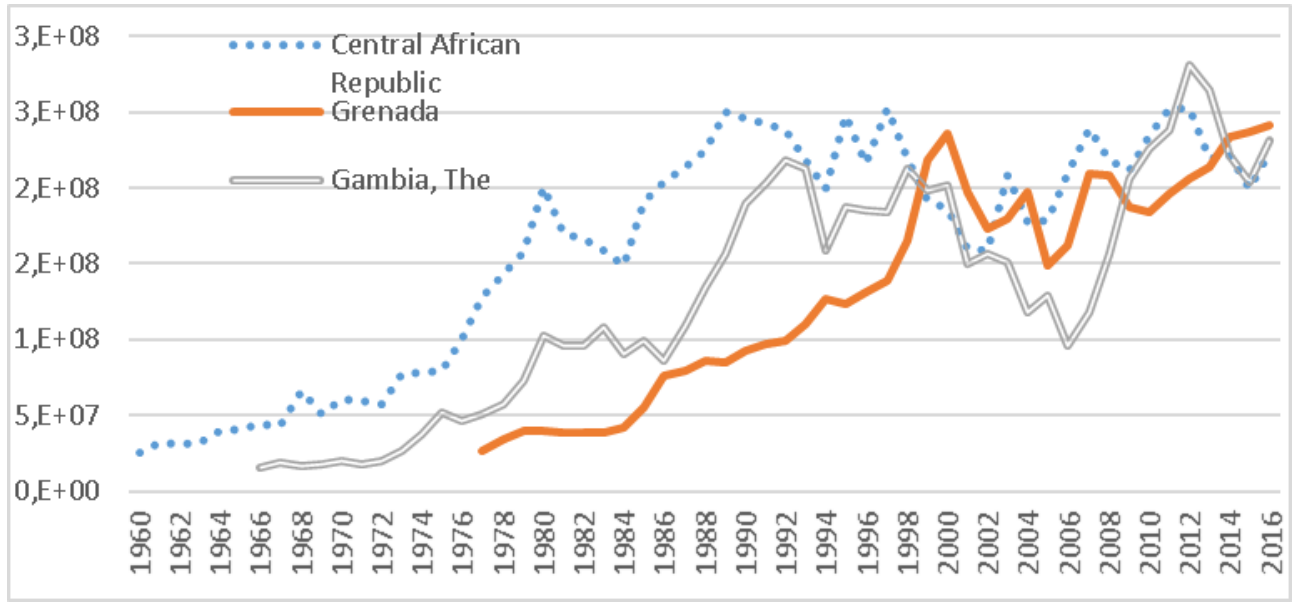

Fig. 2. Data on exports of goods and services for low-exporting countries, us dollar.

- Next the neural network training is carried out on the data and a model of the system is obtained (Fig. 5) [4];

- Then before applying the model we changed the output column to the input, and the output of the model gives us the results of prediction for the next five years;

- Next we checking the results and compare it with the well-known ARIMA [3] time series forecasting method (see full data table [2]).

\section{Results}

First, we describe the results of neural network training, and then the results of applying the neural network model to the time series data.

On the Fig. 3 presented the result of neural network training of the initial data, from the Table 2. In addition, Figure 4 demonstrates the R-value of approximated model, which has a good value $(\mathrm{R}=0.9774)$.

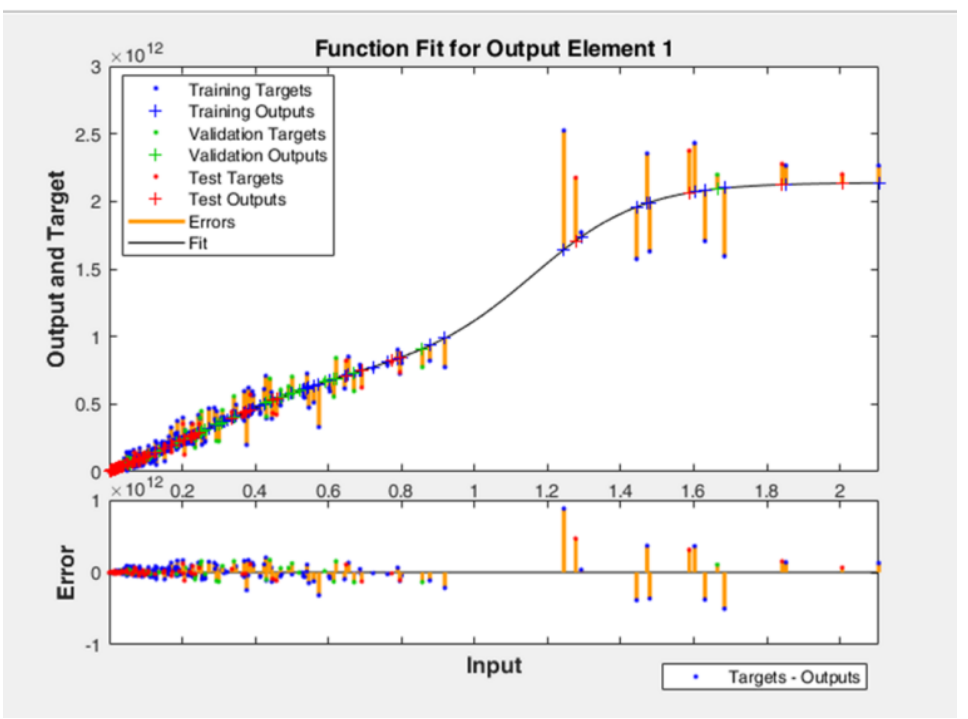

Fig. 3. Function approximation obtained with a neural network. 


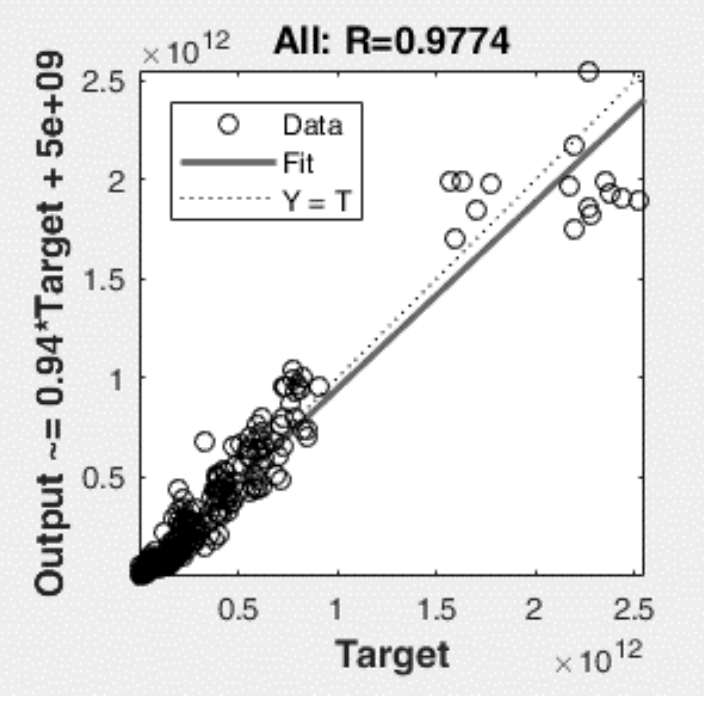

Fig. 4. R-value of approximated data.

The Fig 5 demonstrated the structure of neural network: one input, 10 hidden neurons and one output.

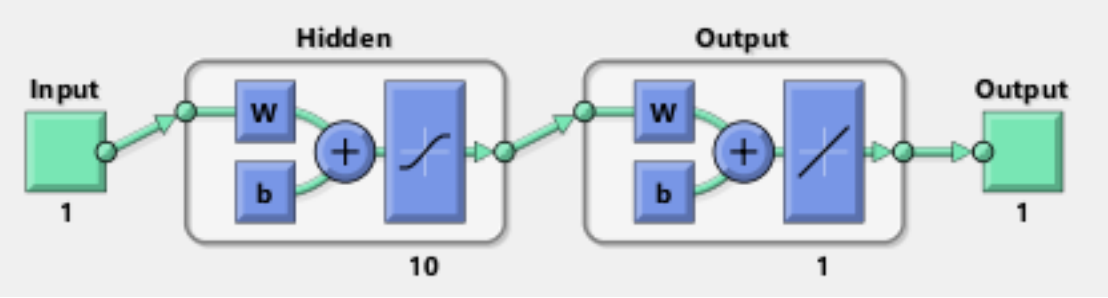

Fig. 5. Structure of neural network.

At this section, examine the results obtained by applying the resulting model to the output data. According to our methodology, we give a column of output data to the model input and get a forecast for five years ahead.

Figures 6 and 7 present the results of the model forecast to 2021 for two segments: for countries with high exports of goods and services, and for countries with low. 


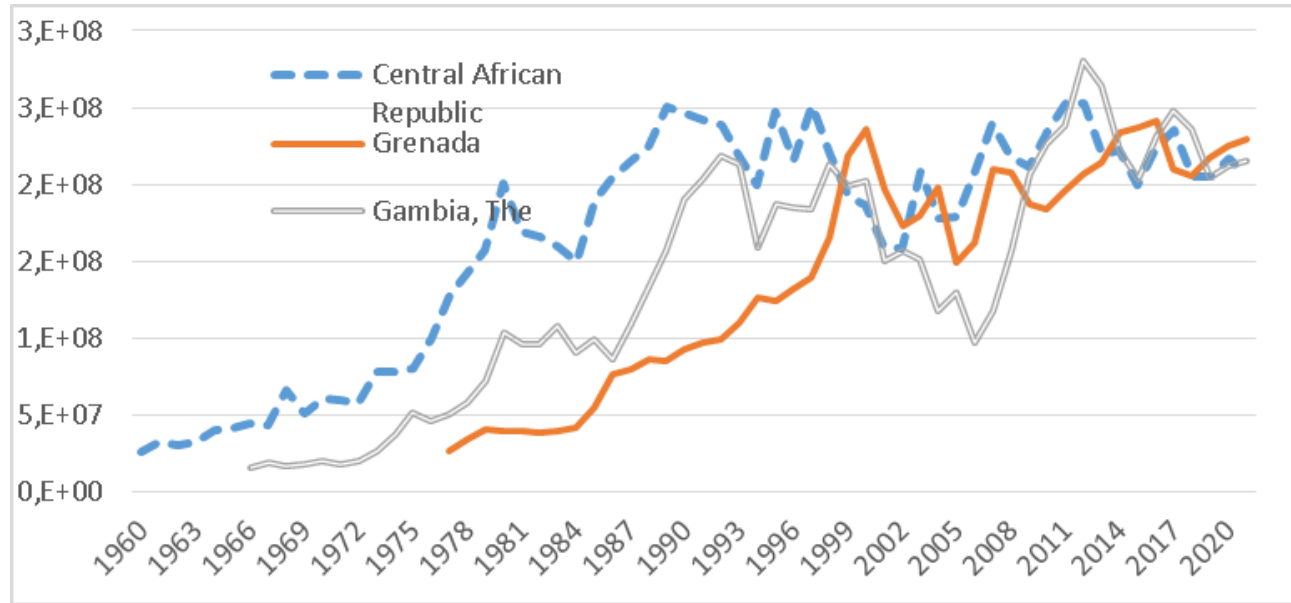

Fig. 6. The result of the forecast of exports of goods and services to 2021, countries with high export, us dollar.

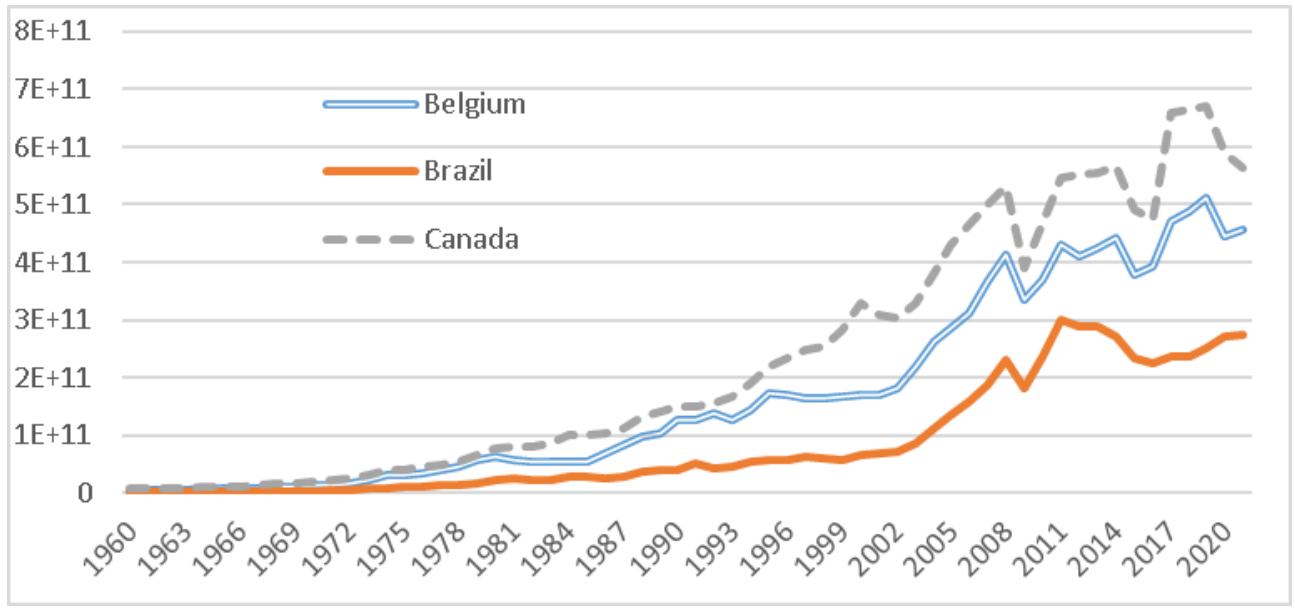

Fig. 7. The result of the forecast of exports of goods and services to 2021, countries with low export, us dollar.

The full table of the results is available here [2].

The comparison of the accuracy of obtained time series forecasting results with the well-known ARIMA method [3] (Fig 8) gives a good similarity. 


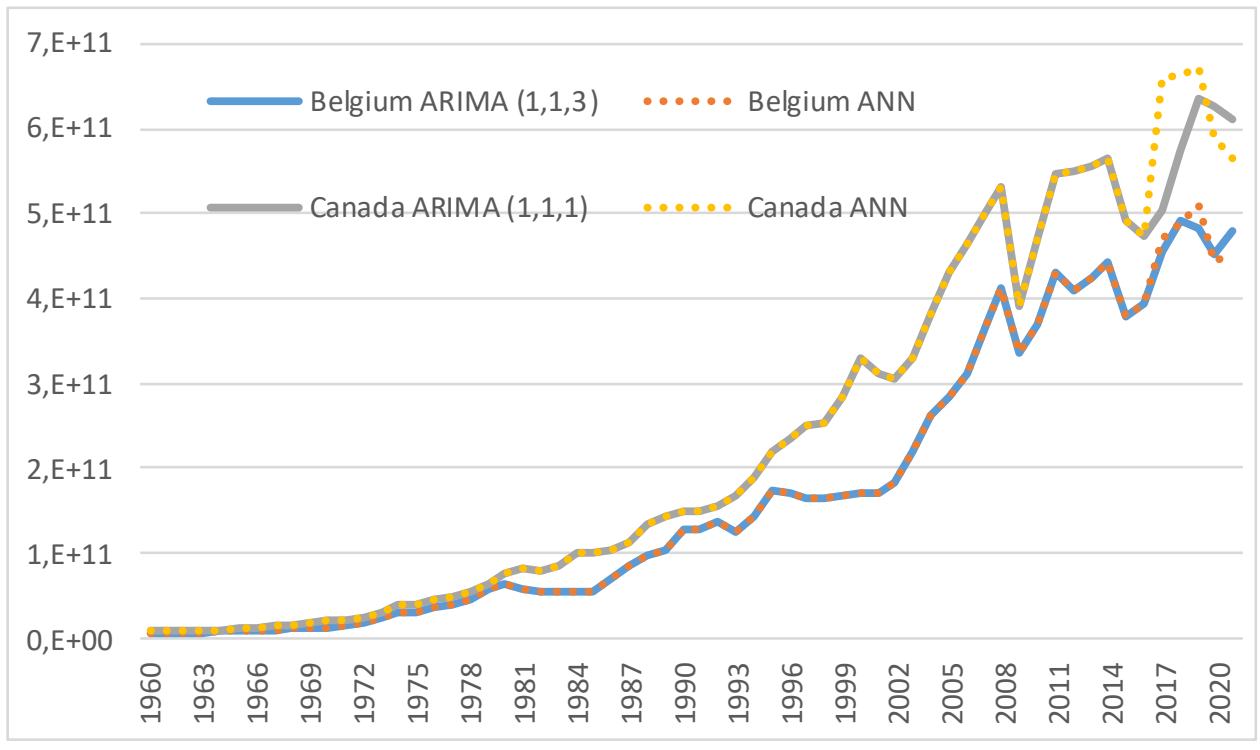

Fig. 8. Comparison of forecasting methods: neural networks and ARIMA method, us dollar.

\section{Discussion}

We think, that the obtained model of the neural networks can be widely used for time series forecasting, together with the well-known methods [5, 6], like:

- Regression forecasting models;

- The autoregressive forecasting model (ARIMA, GARCH, ARDLM);

- Exponential smoothing models (ES);

- Model by maximum similarity sampling (MMSP);

- The model on the Markov chains (Markov chains);

- Model for classification and regression trees (CART);

- Model based on genetic algorithm (GA);

- Model support vector machine (SVM);

- Model based on transfer functions (TF);

- Fuzzy logic model (FL);

Especially if it proved in practice that our method gives better speed of calculation and data preparation and acceptable accuracy of the results.

Let now touch the problem of the importance of segmentation before training the neural network. On the fig. 9 displayed the results of the forecasting of exports of goods and services for low-exporting countries, if the segmentation procedure is not applied. The "data jump" (overestimation) for these countries is well visible, which is well corrected by segmentation procedure (Fig 10). 


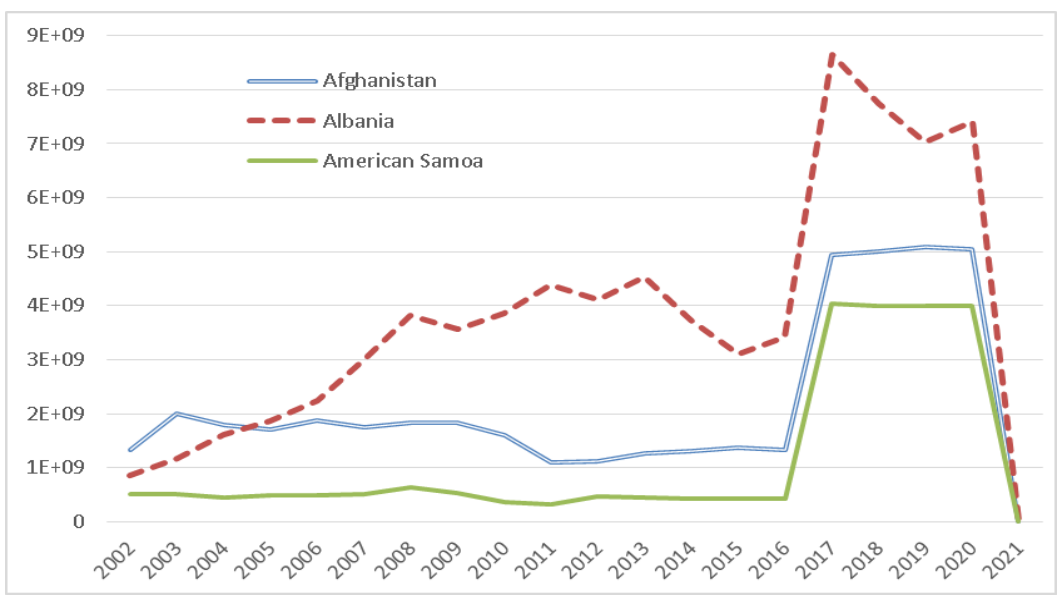

Fig. 9. Forecast of exports of goods and services for low-exporting countries without segmentation.

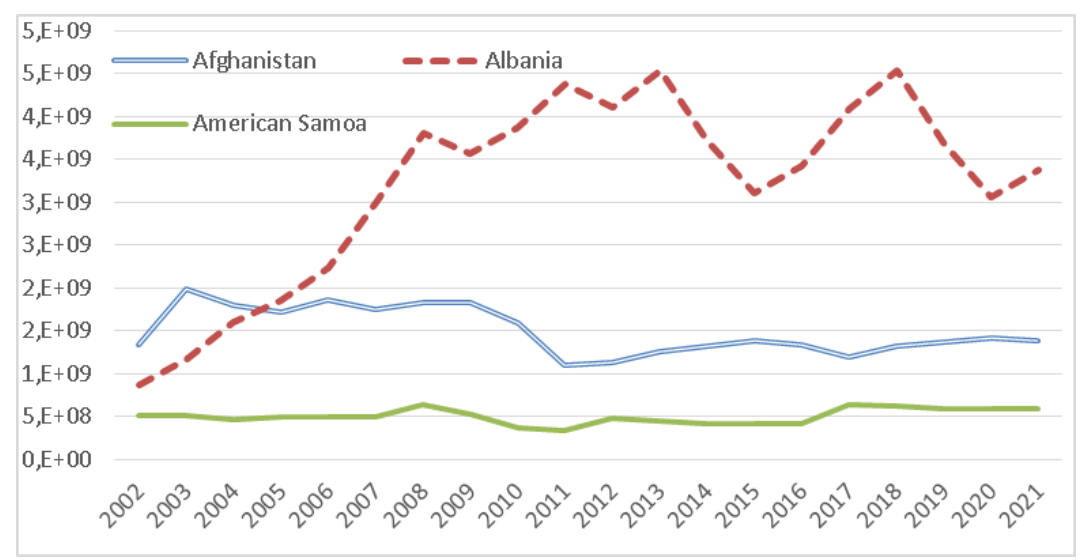

Fig. 10. Forecast of exports of goods and services for low-exporting countries with segmentation.

\section{Conclusions}

The time series forecasting by neural networks made in this new work has the following advantages: fast speed of creation and training of neural network, a small error of approximation (R-value) and a quick algorithm of obtaining the results from neural networks model. It also gives irrelevantly good results of prediction for different types of time series data: with seasonal component, cyclic component or without.

The comparison of neural networks with the ARIMA method gives a good correlation of both approach.

\section{References}

1. World Bank Open Data, https://data.worldbank.org

2. A.G. Somov, The full table of the input data and the results, https://yadi.sk/d/T517kFE3Twp8A

3. A.G. Somov, O.A. Ponomareva, Fund. and App. Res. in Manag. Econ. and Trade 1, 340-350 (2017) 
4. K.P. Murphy, Machine Learning: A Probabilistic Perspective (Cambr., Mass., MIT Press, 2012)

5. V.A. Dubolazov, A.G. Somov, Econ. and Manag. of Manag. Sys. 4.4(26), 411-417 (2017)

6. J. Kałkowska, A.V Kozlov, Decision Making Process for the Knowledge-Based Enterprise: Fuzzy Sets Theory Application to the Strategic Management (Adv. in Intell. Sys. and Comp., 2016) 